\title{
Perfil Epidemiológico dos Co-Infectados pela Neurotoxoplasmose em Portadores da Síndrome da Imunodeficiência Adquirida
}

\author{
Epidemiological Profile of Neurotoxoplasmosis Co-Infected Patients with Acquired \\ Immunodeficiency Syndrome
}

El Perfil Epidemiologico de los Co-Infectados con Toxoplasmosis en Pacientes con Síndrome de Inmunodeficiencia Adquirida

Tâmyssa Simões dos Santos ${ }^{1}$

Clodis Maria Tavares ${ }^{2}$

Eliézel Alves dos Anjos ${ }^{3}$

Daniela Lessa de Carvalho Tavares ${ }^{4}$

Larissa Oliveira Lessa ${ }^{5}$

Vanessa Luiza Lins de Carvalho Silva ${ }^{6}$

\section{Resumo}

A síndrome da imunodeficiência adquirida (SIDA/AIDS) causa uma debilitação do sistema imunológico, deixando o usuário à mercê de doenças oportunistas. Objetivo: $\mathrm{O}$ estudo analisou o perfil epidemiológico dos coinfectados pela neurotoxoplasmose em portadores da síndrome da imunodeficiência adquirida. Método:
Trata-se de um estudo descritivoretrospectivo, com abordagem quantitativa. Foram examinados 108 prontuários de clientes com as referidas patologias, admitidos no Hospital Escola Dr. Hélvio Auto, Maceió-AL, no período de 2005 a 2008. Resultados: Foi observado, no decorrer da pesquisa, um aumento da co-infecção pela neurotoxoplasmose significativo quanto ao gênero masculino, correspondendo a

\footnotetext{
${ }^{1}$ Mestre em Educação em Ciências da Saúde do Instituto Universitário Italiano de Rosário (IUNIR). Graduada em Enfermagem pelo Centro Universitário CESMAC. Autora correspondente: Rua Antônio Cansanção, 1045. Edf. Via Veneto, Ponta Verde. Maceió, Alagoas. Brasil. 57035-190. E-mail: tamyssasimoes@hotmail.com

${ }^{2}$ Doutora da Universidade de São Paulo (USP). Coordenadora do curso de Enfermagem Do Centro Universitário Tiradentes (UNIT). Professora Assistente da Escola de Enfermagem e Farmácia da Universidade Federal de Alagoas (UFAL).

${ }^{3}$ Mestre em Saúde da Criança e Adolescente da Universidade Federal de Alagoas (UFAL).

${ }^{4,5,6}$ Graduanda de enfermagem da Universidade Federal de Alagoas (UFAL).
} 
$62 \%$. A faixa etária mais atingida foi de 25 a 45 anos, a maioria dos pesquisados tinha uma escolaridade do $1^{\circ}$ ao $9^{\circ}$ ano incompleto (fundamental). Foram relevantes, durante a série histórica, 62 casos com LTCD4+ <350 células $/ \mathrm{mm}^{3}$, representando $57,40 \%$ dos prontuários analisados. Porém, os dados denotam um percentual de $13,88 \%$ com LTCD4+ $\geq 350$ células $/ \mathrm{mm}^{3}$, mostrandose um bom parâmetro, indo em objeção à literatura. Os números de óbitos também demonstraram-se altos, 38 casos, denotando o índice de 35,18\%. Conclusão: São irrefutáveis medidas que forneçam o diagnóstico precoce da citada co-infecção, sabendo-se que esta não é de notificação compulsória obrigatória, dificultando nas medidas de controle e prevenção.

Descritores: Síndrome de Imunodeficiência Adquirida; HIV; Toxoplasmose; Toxoplasmose

\section{Cerebral; Perfil de Saúde.}

\section{Abstract}

Objective: to analyze the epidemiological profile of patients coinfected with neurotoxoplasmosis and patients with Acquired Immunodeficiency Syndrome (AIDS).
Method: This is a descriptive, quantitative study. Performed with medical records at Dr. Hélvio Auto, Maceió/AL Hospital, from 2005 to 2008. 108 medical records were reviewed of patients with these pathologies. Results: it was observed that there was an increase in coinfection with neurotoxoplasmosis in patients affected by AIDS, mainly in males, corresponding to $62 \%$. The most affected age group was 25 to 45 years old, the majority of those had an incomplete education. During the historical series, 62 cases with LTCD4 $+<350$ cells / $\mathrm{mm}^{3}$, representing $57.40 \%$ of the medical records analyzed, were relevant during the historical series. The data show $13.88 \%$ with LTCD4 + $\geq 350$ cells / mm3, showing a good parameter. The number of deaths was also high: 38 cases, an index of $35.18 \%$. Conclusion: There are irrefutable measures that provide an early diagnosis of the aforementioned co-infection, knowing that this is not compulsory notification, making it difficult to control and prevent it.

Descriptors:

Acquired

Immunodeficiency Syndrome; HIV; Toxoplasmosis; Toxoplasmosis

\section{Cerebral; Health Profile.}




\section{Resumen}

El síndrome de inmunodeficiencia adquirida (VIH / SIDA) provoca un debilitamiento del sistema inmunológico, dejándole a merced de las enfermedades oportunistas. El objetivo de este estudio fue analizar el perfil epidemiológico de co-infectados con toxoplasmosis en pacientes con síndrome de inmunodeficiencia adquirida. Se trata de un estudio descriptivo y retrospectivo, con un enfoque cuantitativo. Se examinaron 108 expedientes de pacientes con estas enfermedades, admitido en la Escuela de Auto Hospital Dr. Hélvio, MaceióAL, en el período de 2005 a 2008. Se observó durante la investigación, un aumento de la coinfección con toxoplasmosis significativo como el masculino, que corresponde a $62 \%$. El grupo de edad más afectado fue el de 25-45 años, la mayoría de los encuestados tenía una escuela del 1 al 9 años incompletos (fundamental). Eran relevante durante la serie de tiempo, 62 pacientes con CD4 + TL <350 células / mm, que representan $57.40 \%$ de los registros analizados. Sin embargo, los datos indican un porcentaje del 13,88\% con CD4 + TL $\geq 350$ células / $\mathrm{mm} 3$, siendo un buen parámetro, pasando objeción a la literatura. El número de muertes también han demostrado en lo alto, 38 casos, lo que refleja la tasa de 35,18\%. Son medidas irrefutables para el diagnóstico precoz de dicho coinfección, sabiendo que esto no es obligatorio declaración obligatoria, lo que dificulta las medidas de control y prevención.

\section{Descriptores: $\quad$ Síndrome de Inmunodeficiencia Adquirida; VIH; Toxoplasmosis; Toxoplasmosis}

Cerebral; Perfil de Salud.

\section{Introdução}

A AIDS é hoje considerada um dos maiores problemas de saúde pública no Brasil e no Mundo. É uma doença emergente, grave, causada pelo retrovírus HIV (vírus da imunodeficiência humana), que vem se disseminando rapidamente pelo mundo desde 1981. Os infectados pelo HIV evoluem para uma grave disfunção do sistema imunológico, à medida que vão sendo destruídos os linfócitos T CD4 +, uma das principais células - alvo do vírus $^{(1-2)}$.

Ao final de 2008 foi registrado cerca de 33,4 milhões de indivíduos 
vivendo com HIV/Aids em todo o mundo, a África é o continente com maior números de casos $67 \%$, seguido da Ásia, com 14\%. Nas Américas, os Estados Unidos da América (EUA) e o Brasil são os países mais atingidos pela epidemia $^{(3)}$.

Estima-se que 630 mil pessoas vivam hoje com HIV/Aids no país. Foram notificados 608.230 casos de 1980 a 2011, no nordeste foi registrado 78.686 casos, em Alagoas no decorrer desses anos chegou ao somatório de 4.119 , ficando em $6^{\circ}$ lugar dos números de casos do nordeste. Na capital de Alagoas, Maceió, foi descoberto 131 novos casos, em 2011, com registro de 33 óbitos $^{(4)}$.

A síndrome da imunodeficiência adquirida (SIDA/AIDS) causa uma debilitação do sistema imunológico, deixando o paciente à mercê de doenças oportunistas. Uma vez agravada a imunodepressão, o portador da infecção pelo HIV apresenta infecções oportunistas (IO), que podem ser causada por vírus, bactérias, protozoários, fungos e certas neoplasias. O HIV apresenta neurotropismo bastante acentuado, acarretando no surgimento de síndromes neurológicas específicas, especialmente nas fases mais avançadas da infecção ${ }^{(2)}$. Síndrome da Imunodeficiência

A toxoplasmose é a infecção oportunista cerebral mais frequente nos doentes com infecção por HIV. A infecção primária ocorre após a ingestão de carne mal cozida contendo cistos ou mediante da ingestão de oocistos presentes em fezes de gatos e esporulados no ambiente ${ }^{(5)}$. "Essas manifestações clínicas são encontradas com frequência, provavelmente pela reativação, nos diferentes órgãos, das formas latentes dos cistos contendo bradizoítos" (6).

A encefalite é a causa mais comum de dano ao sistema nervoso central em pacientes com síndrome da imunodeficiência adquirida (AIDS), sendo causada pelo protozoário toxoplasma gondii, que pode infectar qualquer uma das células do cérebro, levando à neurotoxoplasmose ${ }^{(7)}$. O SNC é o segundo local mais comum de manifestações clínicas. Isto pode ser explicado pelo fato de o vírus ser neurotrópico e o SNC um "santuário" para ele, além da pobre penetração das drogas antirretrovirais na presença de uma barreira hematoencefálica $\operatorname{intacta}^{(8)}$.

Apresenta-se com início subagudo déficit neurológico focal e massa lesões são detectadas por tomografia 
computadorizada ou ressonância magnética $^{(9)}$.

Atualmente, o diagnóstico presuntivo (provável ou sugestivo) estabelecido pelo 'Centers for Disease Control', baseia-se na presença de achados neurológicos compatíveis (sinais neurológicos focais, alterações do nível ou do conteúdo da consciência, evidência de imagem tomográfica de lesão expansiva, com ou sem realce da substância de contraste), reações sorológicas positivas (presença de anticorpos IgG contra $\mathrm{T}$. gondii), e uma adequada resposta terapêutica ao tratamento anti-T. gondii ${ }^{(10)}$.

A AIDS passou a ser uma doença de notificação compulsória em 22 de dezembro de 1986, com a publicação da Portaria $\mathrm{n}^{\circ} 542$ do Ministério da Saúde, juntamente com a sífilis congênita ${ }^{(11)}$, em contrapartida, a Toxoplasmose não é de notificação obrigatória, sendo registrados alguns casos associados à aids, dados do Departamento de Atenção à Saúde da Secretaria Municipal de Saúde de Maceió- AL (2008), pelo fator magnitude. Porém, na sua ocorrência, os casos são acompanhados pela Instituição Hospital Dr. Hélvio Auto.

Portanto, o interesse em pesquisar o perfil epidemiológico dos indivíduos com HIV/Aids associados a co-infecção neurotoxoplasmose prende-se ao fato de ter atuado como estudante de enfermagem em um serviço público de referência para tratamento de doenças infecto-contagiosas, Hospital Escola Dr. Hélvio Auto - HEHA, em Maceió, e no ato observacional detectar um grande número de pacientes com neurotoxoplasmose. Surgindo assim, a necessidade (dar uma olhada em qual termo você prefere) de traçar o perfil desses pacientes.

Assim, o foco do estudo é identificar o perfil epidemiológico dos indivíduos com HIV/AIDS associados à neurotoxoplasmose. Esta pesquisa pode facilitar a detecção desses portadores através da realização da anamnese pelo enfermeiro, podendo identificar precocemente a possibilidade de um paciente com HIV se infectar pelo toxoplasma.

Diante do exposto, este estudo teve como objetivo analisar o perfil epidemiológico dos portadores da AIDS/SIDA associado à neurotoxoplasmose, com relação as características sociodemográficas (sexo, idade, escolaridade, estado civil e procedência), carga viral e análise dos LTCD4, de 108 pacientes atendidos na instituição Hospital Escola Dr. Hélvio Auto (HEHA). A hipótese desse artigo é que os indivíduos com a co-infecção por neurotoxoplasmose sejam na maioria do 
sexo masculino, solteiros, com nível socioeconômico baixo, proveniente do interior do estado, com carga viral alta e CD4 baixo.

\section{Método}

Tratou-se de um estudo descritivo-retrospectivo, com abordagem quantitativa, tendo como local para desenvolvimento da pesquisa o Hospital Escola Dr.Hélvio Auto HEHA, Maceió/AL. No período de outubro de 2010 à março 2011. A população do estudo detêm-se a pacientes portadores do HIV/AIDS com a co-infecção por neurotoxoplasmose em tratamento na instituição referida.

A amostra foi constituída por 108 prontuários, analisados no período de 2005 à 2008 na instituição relatada anteriormente. Deram entrada 802 portadores do vírus HIV, segundo dados do Núcleo de Vigilância Epidemiológica, desses casos foram registrados 115 com diagnóstico de neurotoxoplasmose, no qual 05 prontuários não foram encontrados e 02 inativos (abandono do tratamento). A pesquisa estabeleceu como critérios de inclusão: prontuários de portadores do AIDS com a neurotoxoplasmose, maiores de 18 anos, que contenham as variáveis pertinentes para o preenchimento do formulário da pesquisa.

Os procedimentos para coleta de dados incluíram: autorização da instituição para coleta de dados. Foi solicitado o declínio do Termo de Consentimento Livre e Esclarecido (TCLE), e os pacientes não foram identificados nominalmente no instrumento de pesquisa, com a finalidade de manter o sigilo das informações.

Foi utilizado um formulário para coleta de dados, contendo as variáveis: procedência, faixa etária, sexo, escolaridade, estado civil, quantidade de carga viral e linfócitos $\mathrm{T}$ CD4+ (LTCD4+). Foram analisados os dados após um agrupamento no Microsoft Office Excel versão 2007, sendo calculadas as frequências absolutas (número de casos) e relativas (percentuais). Os dados foram apresentados na forma tabular e gráfica, para melhor compreensão. A pesquisa foi submetida à apreciação do Comitê de Ética do Centro Universitário Maceió - CESMAC sob o protocolo de $n^{\circ} 782 / 09$.

\section{Resultados}


Em todo o período estudado, apresentaram diagnóstico para foram registrados 802 pacientes, com neurotoxoplasmose.

AIDS, destes, $115 \quad(14,33 \%)$

Tabela 1. Distribuição das Variáveis Sociodemográficas de Usuários com AIDS e Neurotoxoplasmose.

\begin{tabular}{|c|c|c|}
\hline Variáveis sociodemográficas & $\mathbf{N}$ & $\%$ \\
\hline \multicolumn{3}{|l|}{ Sexo } \\
\hline Masculino & 67 & 62 \\
\hline Feminino & 41 & 38 \\
\hline \multicolumn{3}{|l|}{ Idade (anos) } \\
\hline$\geq 18$ & 02 & 1,8 \\
\hline $20|-| 24$ & 07 & 6,5 \\
\hline $25|-| 45$ & 83 & 76,85 \\
\hline$>45$ & 16 & 14,85 \\
\hline \multicolumn{3}{|l|}{ Escolaridade } \\
\hline Analfabeto & 18 & 16,6 \\
\hline Alfabetizado & 08 & 7,4 \\
\hline $1^{\circ}$ ao $9^{\circ}$ ano incompleto (fundamental) & 56 & 51,8 \\
\hline $1^{\circ}$ ao $3^{\circ}$ ano incompleto (ensino médio) & 25 & 23 \\
\hline Ensino superior compl/incompl & 1 & 1 \\
\hline \multicolumn{3}{|l|}{ Estado Civil } \\
\hline Solteiro & 68 & 63 \\
\hline Casado & 30 & 27,8 \\
\hline Separado/divorciado & 07 & 6,5 \\
\hline Viúvo & 03 & 2,7 \\
\hline \multicolumn{3}{|l|}{ Procedência } \\
\hline Capital/Maceió & 55 & 51 \\
\hline Outros municípios/AL & 53 & 49 \\
\hline Total & 108 & 100,0 \\
\hline
\end{tabular}

Fonte: SAME/HEHA/UNCISAL, 2010. 
Dos 108 clientes registrados com AIDS/neurotoxoplasmose, $38(35,18 \%)$ evoluíram para óbito.

A Tabela 1 refere-se à distribuição das variáveis sociodemográficas, dos usuários do sexo masculino, que responderam a maioria, totalizando (62\%), com idade entre 25 a 45 anos, com relação à escolaridade, 56 (51,8\%) estudaram do $1^{\circ}$ ao $9^{\circ}$ ano incompleto fundamental e apenas $01(1 \%)$ tinha ensino superior. Quanto à procedência, $51 \%$ dos usuários eram da capital de Alagoas, e 49\% nos demais municípios do estado, em relação ao estado civil, a maioria era solteiro $(68 \%)$.

\section{Gráfico 1. Distribuição de Números de Casos de Toxoplasmose/AIDS, Segundo a Contagem de Linfócito T CD4+.}

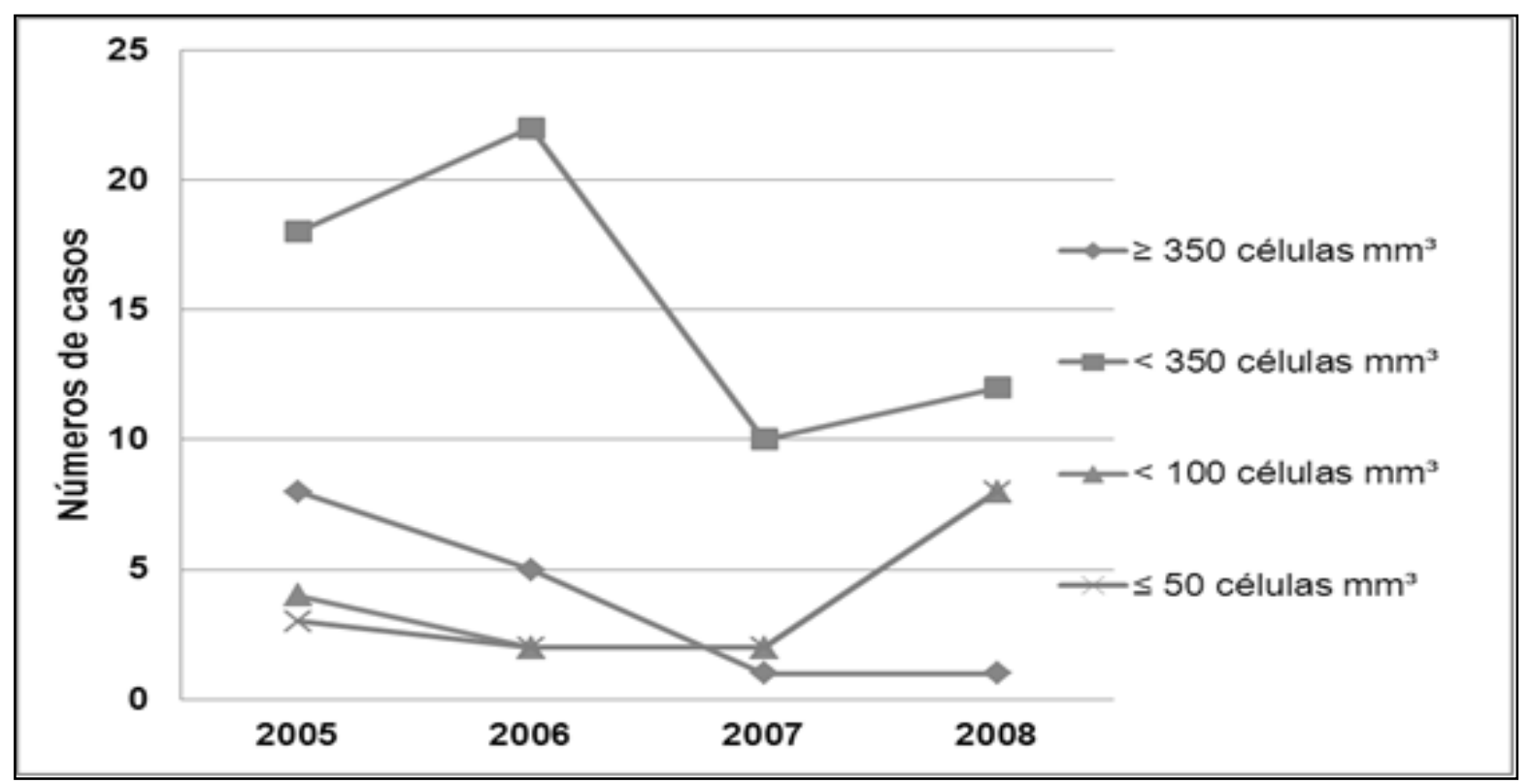

Fonte: SAME/HEHA/UNCISAL, 2010.

O gráfico 1, representa a contagem de carga viral. A maior parte dos pacientes, 54 (50\%) pacientes apresentaram alta carga viral (> 10.000 cópias). Quanto ao parâmetro indetectável, que evidencia bom prognóstico, foram encontrados 26 $(24,07 \%)$ casos.
O gráfico 2, refere-se a relação entre o número de casos de AIDS correlacionando ao percentual de neutoxoplasmose durante a série histórica. No ano de 2005, foram notificados 157 casos de AIDS, dos quais $\quad 21 \% \quad$ apresentaram neurotoxoplasmose, corroborando para o índice mais relevante durante a série 
histórica. O ano de 2008 foi marcado com maior números de casos notificados de AIDS, 242, no entanto, o índice para co-infecção neurotoxoplasmose mostrou-se menor $12,8 \%$.

\section{Gráfico 2. Distribuição de Números de Casos de Neurotoxoplasmose/AIDS Correlacionados com a Contagem de Carga Viral.}

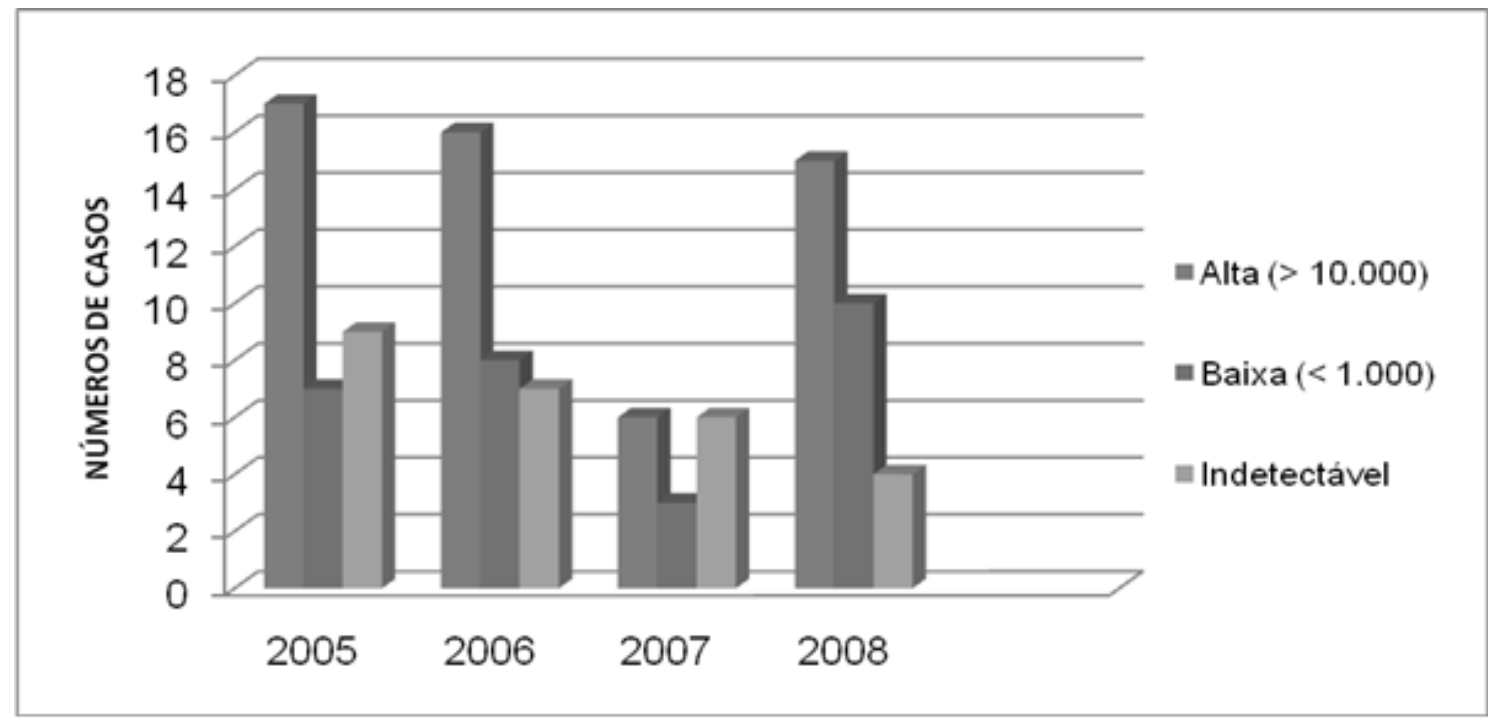

Fonte: SAME/HEHA/UNCISAL, 2010.

\section{Gráfico 3. Relação entre o Número de Casos de AIDS e Percentual da Neurotoxoplasmose.}

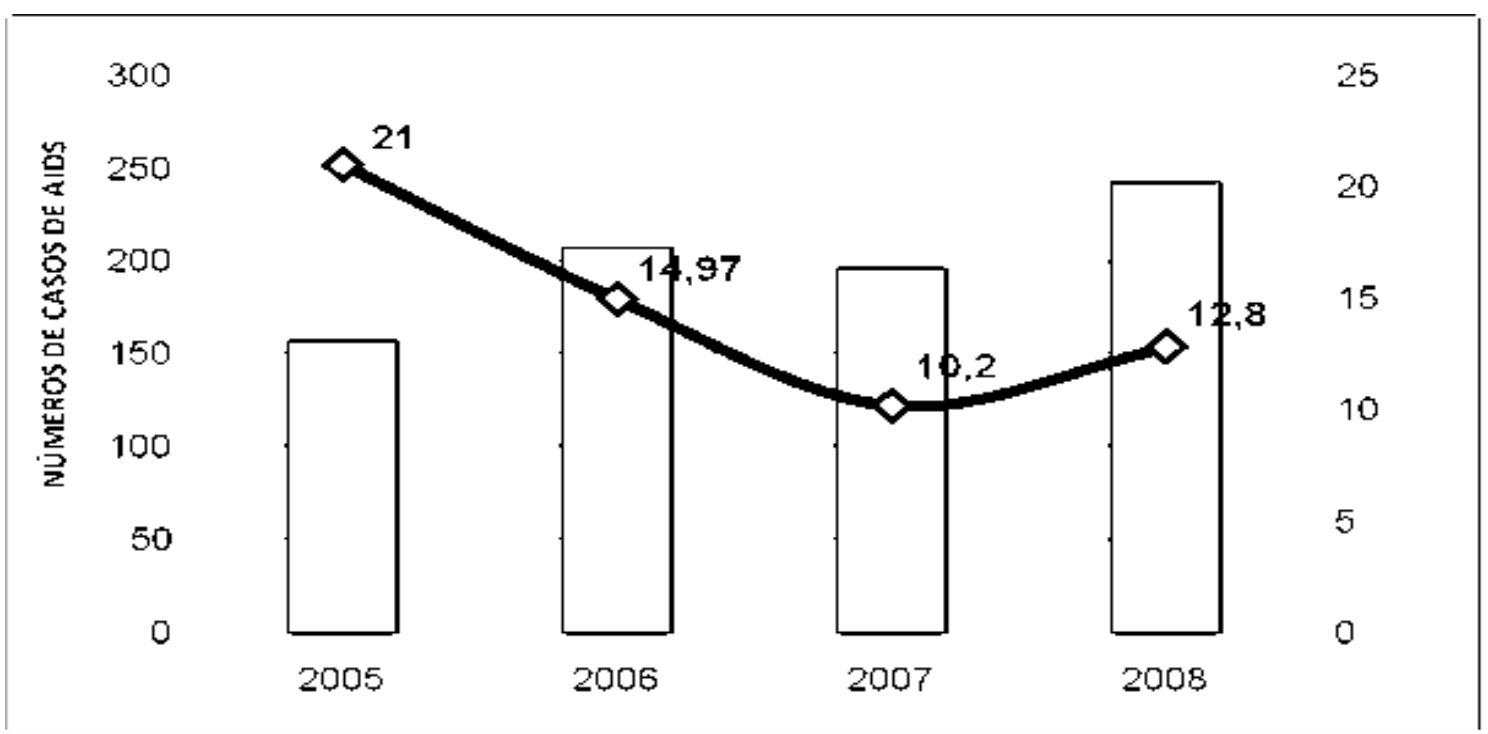

Fonte: NVE/HEHA/UNCISAL, 2010.

Discussão

A infecção pelo HIV/AIDS atualmente representa um problema 
individual e de saúde pública. De

acordo com os dados da Organização Mundial de Saúde (OMS), a AIDS deve ser considerada como uma epidemia mundial, sendo necessário um esforço global para controlar sua transmissão.

Desta forma o perfil epidemiológico torna-se um instrumento importante, já que através deste, pode-se conhecer as características desses indivíduos para a formulação de estratégias de ação e prevenção para a implementação de programas e projetos realmente eficazes de controle deste agravo ${ }^{(13)}$.

A implantação de um formulário que aborde as principais caracteristicas de um potencial portador de doenças oportunistas nos serviços de assistência especializada e nas instituições de doenças infecto-contagiosas, levaria a equipe de saúde tomar medidas de promoção e prevenção aos portadores do HIV/AIDS, e ao alcance do diagnóstico precoce. Estas condutas reduziriam as infecções oportunistas dando uma melhor qualidade de vida a esses pacientes.

A redução das internações hospitalares e óbitos relacionados à doença, bem como o aumento significativo da sobrevida dos indivíduos portadores do HIV, foram proporcionados devido a chegada dos antirretrovirais (ART), alavancando uma mudança progressiva e significativa do perfil de morbimortalidade da infecção do HIV no Brasil ${ }^{(14)}$. Com o advento da terapia dos ART, a incidência de toxoplasmose tem sido reduzida, com uma taxa de soroconversão para o Toxoplasma gondi de $2 \%$ ao ano em pacientes com infecção pelo $\operatorname{HIV}^{(15)}$. "Estima-se que pelo menos metade dos pacientes soropositivos toxoplasma vai desenvolver toxoplasmose cerebral"(17).

Durante o período do estudo chegou-se ao acumulativo de 802 casos de HIV/Aids, sendo 115 (14,33\%) dos pacientes apresentaram diagnóstico para neurotoxoplasmose. Por se tratar de uma doença que na grande maioria dos casos deixa sequelas cerebrais ou mesmo leva à morte, a saúde pública deve implantar medidas preventivas para redução desse percentual. Câmara et al. apud Souza $^{(18)}$ et al., retratam em sua pesquisa a análise de lesões neurológicas em 154 pacientes necropsiados com AIDS, nos quais encontraram toxoplasmose em 60 $(38,9 \%)$ casos.

Ferreira $^{(19)}$ ressalta que, nos mais variados climas e condições sociais, a porcentagem de indivíduos positivos 
com o T. gondii varia de 20 a $83 \%$ da população mundial, sendo provavelmente o protozoário mais difundido entre a população humana e animal.

Autores relatam que $50-70 \%$ dos casos só descobrem que estão com Toxoplasmose Cerebral, após o diagnóstico da AIDS. Detalha ainda que $20-25 \%$ dos portadores dessa coinfecção vão a óbito e quase metade dos pacientes fica com sequelas neurológicas ${ }^{(20)}$. Na presente pesquisa, foi observado que dos 108 pacientes, 38 evoluíram para óbito, correspondendo a $35,18 \%$ dos casos, uma porcentagem alta, em relação, ao citado por outros autores.

Em relação ao gênero, no Brasil foi notificado, durante o período de 1980 a junho de 2011, 608.230 casos de Aids, sendo $397.662(65,4 \%)$ no sexo masculino e $210.538(34,6 \%)$ no sexo feminino $^{(4)}$, no entanto, a relação homem:mulher vem diminuindo ao longo dos anos em todo território brasileiro $^{(1)}$. No presente estudo o gênero masculino e estado civil solteiro mostram-se prevalente, assemelhandose a outros estudos ${ }^{(1,18,21)}$.

Quanto a faixa etária, predominou entre 25 a 45 anos, autores descrevem que pode-se observar um maior número de casos entre 20 e 49 anos tanto no homem quanto na mulher ${ }^{(1,22)}$. Pereira $^{(23)}$ et al., afirma que a AIDS continua sendo uma das principais causas de morte entre os jovens adultos nos grupos etários entre 25 e 44 anos, apesar da inclusão da terapia dos antirretrovirais.

Da variável escolaridade é possível verificar que está diretamente correlacionada ao nível de informação do indivíduo. Uma população desinformada está mais suceptível ao adoecimento. $\mathrm{Na}$ presente pesquisa 56 $(51,8 \%)$ dos pacientes estudaram do $1^{\circ}$ ao $9^{\circ}$ ano incompleto (fundamental) e apenas $1(1 \%)$ tinha nível superior.

Parenti $^{(24)}$, ressalta que $59 \%$ dos pacientes analisados estudaram de 4 a 7 anos, e apenas 3\%, 8 a 11 anos. Rodrigues e Castilho ${ }^{(22)}$, apontam em seu estudo a predominância da categoria heterossexual, incluindo mulheres, jovens e pessoas com pouca, ou nenhuma, escolaridade, na rede de causalidade da doença.

Tratando-se do modo de transmissão da toxoplasmose, esta baseia-se na ingestão de oocistos provenientes do solo, areia, latas de lixo contaminados com fezes de gatos infectados e da Ingestão de carne crua e mal cozida infectada com cistos, 
especialmente carne de porco e carneiro $^{(16)}$, levantando-se a hipótese que pacientes HIV/AIDS que residem no interior são mais susceptíveis a toxoplasmose. Porém, neste estudo não houve uma diferença significativa, demonstrando uma equivalência entre capital e interior.

Em 1998, com o objetivo de permitir a vigilância epidemiológica mais precoce da AIDS, foi introduzido o critério de notificação baseado na quantificação sérica de linfócitos $\mathrm{T}$ CD4+ (doravante chamado de 'CD4'para pessoas com contagem de linfócitos T CD4+ inferior a 350 células $\left./ \mathrm{mm}^{3}\right)^{(11)}$.

A contagem de linfócitos T CD4+ estabelece o risco de progressão para aids e morte, torna-se portanto, o indicador laboratorial mais importante em pacientes assintomáticos, para definir o momento de iniciar o tratamento. Se estas células estiverem próximas a $350 / \mathrm{mm}^{3}$, pode-se apoiar a decisão de iniciar o tratamento, essa contagem deve ser realizada de 3-6 meses, e repitir quando os valores forem discrepantes ou tiverem tendência à queda $^{(25)}$.

Em relação a profilaxia primária da toxoplasmose, esta objetiva-se evitar o desenvolvimento neurotoxoplasmose, sendo recomendada para pacientes com $\operatorname{IgG}$ positivo para toxoplasma e contagem de linfócitos TCD4 + < 200 células $/ \mathrm{mm}^{3(25)}$, o que assemelha-se com o estudo de Mesquita $^{(10)}$, que descreve: estima-se que 25 a $50 \%$ dos pacientes com aids que apresentam anticorpos IgG anti-T. gondii e menos de 200 células $\mathrm{T}$ $\mathrm{CD} 4+/ \mu \mathrm{L}$ de sangue desenvolviam toxoplasmose cerebral. Uma pesquisa realizada em Edimburgo, capital escocesa, revela que $48 \%$ dos pacientes com sorologia positiva para toxoplasma e que tinham uma contagem de CD4 $<50$ células $/ \mathrm{mm}^{3}$ desenvolveram toxoplasmose cerebral ${ }^{(17)}$.

Nesta pesquisa foi encontrado 62 $(57,40 \%)$ casos com linfócitos T-CD4 + $<350$ células $/ \mathrm{mm}^{3}$, mostrando-se bastante próximo dos resultados encontrados na literatura. No entanto, chama-nos a atenção que 15 casos, representando $13,88 \%$ possuíam linfócitos T-CD4 $+\geq 350$ células $/ \mathrm{mm}^{3}$, o que nos revela que mesmo apresentando um bom parâmetro de linfócitos T-CD4, ainda assim, o paciente pode desenvolver toxoplasmose cerebral. Medidas profiláticas e parâmetros de iniciação de tratamento devem passar por momento de avaliação. 
Dentre a contagem da carga viral é realizada na $1^{\mathrm{a}}$ consulta e após quando os linfócitos T CD4 + estiverem próximos a 350 células $/ \mathrm{mm}^{3(25)}$. A replicação viral é dinâmica e contínua e, durante a fase aguda da doença, a carga viral é de aproximadamente $10^{5}$ a $10^{7}$ cópias/mL. Esses níveis reduzem com a presença do linfócito $\mathrm{T}$ citotóxicas, mantendo-se posteriormente constante. A partir dessa fase, leva a progressão para AIDS e o tempo médio de incubação é de 5 a $10 \operatorname{anos}^{(16)}$. Pode ser visto no decorrer do estudo que a maioria dos pacientes $54 \quad(50 \%)$ apresentaram alta taxa viral (> 10.000 cópias), que já era esperado, no entanto, apesar da infecção pelo toxoplasma significar que o paciente está gravemente comprometido, foi encontrado $26(24,07 \%)$ casos com o parâmetro indetectável, o que evidencia bom prognóstico.

Mediante o exposto constata-se que definir o perfil epidemiológico dos portadores de HIV/Aids associados a neurotoxoplasmose tornou-se uma árdua tarefa, devido o Brasil ter uma epidemia multifacetada, praticamente a cada ano muda-se a faixa etária, o gênero, estado civil dos acometidos. Brito apud Silva ${ }^{(1)}$ et al. "caracteriza a disseminação do HIV no Brasil como uma epidemia multifacetada, que não possui um perfil epidemiológico único em todo o território brasileiro, mas um mosaico de subepidemias regionais motivadas pelas desigualdades socioeconômicas".

É importante que medidas eficazes de controle das doenças oportunistas sejam adotadas. Faz-se necessário, que os gestores de saúde encarem como um problema de Saúde Pública, implementando estratégias de prevenção e capacitando os profissionais de saúde que atuam nesta área, para que os mesmos, fiquem mais atentos durantes as consultas aos potenciais portadores de doenças oportunistas.

Como limitações, cita-se a dificuldade do acesso aos prontuários no SAME da instituição pesquisada, a falta de registros nos prontuários dos profissionais de saúde, a restrição de artigos cientificos atuais que abordem sobre a temática neurotoxoplasmose.

\section{Conclusão}

Concluindo-se que o perfil desses portadores, na sua maioria, tem baixo índice de escolaridade, o que indica que estão relacionados com nível socioeconômico baixo. Diferente do que 
era esperado na hipótese deste estudo, notou-se que houve uma equivalência entre a transmissão dos casos no interior e na capital. Entretanto, confirma-se a hipótese de que o sexo masculino é o mais acometido pela HIV/AIDS e consequentemente pela toxoplasmose, devido a cultura sexual machista, onde o prazer, gosto pela aventura e a impetuosidade acabam levando os homens a terem relações sexuais com múltiplas parceiras e sem proteção, expondo-se mais ao risco, contribuindo para o aumento da predominância da soro positividade para o HIV. Uma outra hipótese liga-se ao fato da maioria dos homem terem o mal hábito de ingerir carnes cruas/mal passadas, se estas estiverem contaminadas pelo toxoplasma, podem levar a infecção da toxoplasmose, e posteriormente a toxoplasmose cerebral. A variável escolaridade é confirmada ao observar que a maioria dos portadores apresentaram nível de escolaridade muito baixo, o que leva a uma baixa renda e um baixo nível de conhecimento em educação em saúde.

Ao avaliar os exames laboratoriais e verificar através das evoluções médicas e de enfermagem, pode ser visto que tais pacientes apresentaram um sistema imunológico com baixas concentrações de células de LTCD4 ( $<350$ células mm3), o que não justifica, pois, na atenção pública são ofertados os retrovirais, que diminuem a carga viral e consequentemente aumenta as células de LTCD4. Além do tratamento, há um acompanhamento especializado da equipe interdisciplinar (médicos infectologistas, enfermeiros, assistente social, psicólogos, fisioterapeutas) que é de suma importância para adesão ao tratamento farmacológico. Nota-se a responsabilidade da equipe de saúde para orientar esses pacientes na busca de uma qualidade de vida e os cuidados necessários para não contaminar seus parceiros. Um dado alarmante é que a grande parte dos pacientes que apresentaram a neurotoxoplasmose haviam dado entrada na unidade hospitalar várias vezes e pelo histórico clínico percebe-se que não aderiram ao tratamento. Sugiro que novas pesquisas sejam realizadas nesta área, visto que, o número de pessoas contaminadas pelo HIV vem aumentando e nesta mesma linha as doenças oportunistas.

\section{Referências}

1. Silva SFR, Pereira MRP, Neto RM, Ponte MF, Ribeiro IF, Costa PFTF et al. AIDS no Brasil: uma epidemia em transformação. RBAC, 2010;42(3):20912. 
2. Ministério da Saúde (BR). Secretaria de Vigilância em Saúde. Departamento de Vigilância Epidemiológica. Doenças infecciosas e parasitárias: guia de bolso/ Ministério da Saúde, Departamento de Vigilância Epidemiológica. 8 ed. rev Brasília: Ministério da Saúde; 2010.

3. UNAIDS. Report on the global AIDS epidemic. Geneva; 2009.

4. Boletim Epidemiológico Aids. DST. Ano Vlll - $n^{\circ} 1,01^{\circ}$ a $26^{\circ}$ semanas epidemiológicas - janeiro a junho de 2011. Versão Preliminar - Brasília 2011 [citado em 12 dez.2011]. Disponível em: http://www.aids.gov.br /sites/default/files/anexos/publicacao/20 11/50652/vers_o_preliminar_69324.pdf.

5. Siqueira EC. Avaliação de pacientes admitidos no Instituto de Infectologia Emílio Ribas com doença definidora de aids, sem diagnóstico prévio de HIV/AIDS, no período de janeiro a dezembro de 2007 [monography]. São Paulo: Instituto de Infectologia Emílio Ribas; 2008.

6. Costa TL, Silva MG, Avelar JB, Amaral WN, Avelino MM, Castro AM. Toxoplasma gondii: toxoplasmose com ênfase no diagnóstico. Revista de Patologia Tropical. UFG. 2008;37(3):191-07.

7. Nogui FLN, Mattas S, Turcato GJ, Lewi DS. Neurotoxoplasmosis diagnosis for HIV-1 patients by realtime PCR of cerebrospinal fluid. Brazilian Journal of Infectious Diseases. 2009;13(1): [cerca de 9p].

8. Christo PP. Alterações cognitivas na infecção pelo HIV e Aids. Rev Assoc Med Bras. 2010; 56 (2): 242-47.
9. Sardar P, Bandyopadhyay D, Roy D, Guha P, Guha G, Banerjee AK. Non Tuberculous Mycobacteria and Toxoplasma Co-Infection of the Central Nervous System in a Patient with AIDS. The Brazilian Journal of Infectious Diseases. 2009;13(6):449-51.

10. Mesquita RT. Diagnóstico molecular da toxoplasmose cerebral: comparação de diferentes marcadores utilizados na PCR para detecção de Toxoplasma gondii em pacientes com AIDS [dissertation]. São Paulo: Faculdade de medicina de São José do Rio Preto; 2010:90.

11. Ministério da Saúde (BR). Secretaria de Vigilância em Saúde. Critérios de definição de casos de AIDS em adultos e crianças: Programa Nacional de DST e Aids. Brasília: Ministério da Saúde; 2005.

12. Minayo MC. O desafio do conhecimento: pesquisa qualitativa em saúde. Rio de Janeiro: Abrasco; 2007.

13. Feitosa BC, Carvalho NB, Ferreira PN, Fonseca PF. Perfil epidemiológico dos portadores do vírus HIV/AIDS: evidências na literatura de 1997 a 2009. Buenos Aires. Revista Digital. 2011; 16(163).

14. Ministério da Saúde (BR). Brasil é referência na assistência a soropositivos, diz diretor-executivo do Fundo Global para Aids. 2011 [citado em 9 dez 2011]. Disponível em: http://www.aids.gov.br/noticia/2011/bra sil_e_referencia_na_assistencia_soropos itivos_diz_diretor_executivo_do_fundo _global_. 
15. Maliska ICA, Padilha MICS. AIDS: a experiência da doença e a construção do itinerário terapêutico. Rev. Eletr. Enf. UFSC. 2007;9(3):68799.

16. Veronesi R. Tratado de infectologia. São Paulo: Atheneu; 2005; 3.

17. Laing RBS, Flegg PJ, Brettle RP, Leen CLS, Burns SM. Clinical features, outcome and survival from cerebral toxoplasmosis in Edinburgh AIDS patients. 2011 [citado em 02 dez.2011]. Disponivel em: http://ijsa.rsmjournals. com/content/7/4/258.abstract.

18. Souza SLS, Feitoza PVS, Araújo JR, Andrade RV, Ferreira LCL. Causas de óbito em pacientes com síndrome da imunodeficiência adquirida, necropsiados na Fundação de Medicina Tropical do Amazonas. Revista da Sociedade Brasileira de Medicina Tropical. 2008;41(3):247-51.

19. Ferreira IMR. Genotipagem de isolados de Toxoplasma gondii em pacientes com Aids e toxoplasmose cerebral [thesis]. São Paulo; 2008:94 p.

20. Remírez MS, Ballabriga ASO, Rodríguez GMC, Frías MTA, González CA. Insuficiencia renal por sulfadiazina en paciente $\mathrm{VIH}$ con toxoplasmosis cerebral. Anales de Medicina Interna; 2005;22(8):15p.

21. Alves JM, Magalhães V, Matos MAG. Avaliação ofalmológica em pacientes com AIDS e neurotoxoplasmose. Revista da Sociedade Brasileira de Medicina Tropical. 2010;43(1):36-0.
22. Rodrigues-Júnior AL, Castilho EA. AIDS e doenças oportunistas transmissíveis na faixa de fronteira brasileira. Revista da Sociedade Brasileira de Medicina Tropical. 2010;43(5):542-47.

23. Pereira CCA, Machado CJ, Rodrigues RN. Perfis de causas múltiplas de morte relacionadas ao HIV/AIDS nos municípios de São Paulo e Santos, Brasil, 2001. Cad. Saúde Pública. 2007;23(3):645-55.

24. Parenti CF, Pereira LMR, Brandão ZS, Silvério APC. Perfil dos pacientes com aids acompanhados pelo Serviço de Assistência Domiciliar Terapêutica do Município de Contagem, Estado de Minas Gerais, Brasil, 2000-2003. Minas Gerais: Epidemiologia e Serviço de Saúde; 2005;14(2):91-6.

25. Ministério da Saúde (BR). Secretária de Vigilância em Saúde. Programa Nacional de DST e Aids Recomendações para Terapia Antiretroviral em Adultos Infectados pelo HIV: 2008/Ministério da Saúde, Secretaria de Vigilância em Saúde, Programa Nacional de DST e Aids. 7a ed. (Série Manuais $n^{\circ}$ 2). Brasília: Ministério da Saúde; 2008. 